Article

\title{
The Impact of Measures Recommended by the Government to Limit the Spread of Coronavirus (COVID-19) on Physical Activity Levels, Quality of Life, and Mental Health of Brazilians
}

\author{
Dihogo Gama de Matos ${ }^{1, *} \mathbb{C}^{\text {, Felipe J. Aidar }}{ }^{1,2,3}{ }^{\mathbb{D}}$, Paulo Francisco de Almeida-Neto ${ }^{4}$, \\ Osvaldo Costa Moreira ${ }^{5}$, Raphael Fabrício de Souza 1,2 (D), Anderson Carlos Marçal 1,2, \\ Lucas Soares Marcucci-Barbosa ${ }^{6}$ D, Francisco de Assis Martins Júnior ${ }^{6}$, Lazaro Fernandes Lobo ${ }^{6}$, \\ Jymmys Lopes dos Santos ${ }^{1}$, Ialuska Guerra ${ }^{1}$, Anselmo de Athayde Costa e Silva ${ }^{7}$, \\ Eduardo Borba Neves ${ }^{8}\left(\mathbb{D}\right.$, Breno Guilherme de Araújo Tinoco Cabral ${ }^{4}$, Victor Machado Reis 9 \\ and Albená Nunes-Silva ${ }^{6}$ \\ 1 Group of Studies and Research of Performance, Sport, Health and Paralympic Sports-GEPEPS, \\ Federal University of Sergipe, UFS, Sergipe 49100-000, Brazil; fjaidar@academico.ufs.br (F.J.A.); \\ raphaelctba20@hotmail.com (R.F.d.S.); acmarcal@academico.ufs.br (A.C.M.); \\ jymmys@academico.ufs.br (J.L.d.S.); ialuskaguerra@gmail.com (I.G.) \\ 2 Department of Physical Education, Federal University of Sergipe-UFS, Sergipe 49100-000, Brazil \\ 3 Program of Physiological Science, Federal University of Sergipe (UFS), São Cristovão, \\ Sergipe 49100-000, Brazil \\ 4 Department of Physical Education, Federal University of Rio Grande do Norte, Natal 59078-970, Brazil; \\ paulojitte@ufrn.edu.br (P.F.d.A.-N.); brenotcabral@reitoria.ufrn.br (B.G.d.A.T.C.) \\ 5 Institute of Biological Sciences and Health, Campus Florestal, Federal University of Viçosa, \\ Viçosa 35690-000, Brazil; osvaldo.moreira@ufv.br \\ 6 Laboratory of Inflammation and Exercise Immunology, Sports Center, Physical Education School, Federal \\ University of Ouro Preto (UFOP), OuroPreto 35400-000, Brazil; lucas.barbosa@aluno.ufop.edu.br (L.S.M.-B.); \\ francisco.junior@aluno.ufop.edu.br (F.d.A.M.J.); lazaro.lobo@aluno.ufop.edu.br (L.F.L.); \\ albena.silva@ufop.edu.br (A.N.-S.) \\ 7 Graduate Program in in Physical Education, Pará Federal University, Belém, Pará 66075-110, Brazil; \\ anselmocs@ufpa.br \\ 8 Brazilian Army Research Institute of Physical Fitness (IPCFEx), Rio de Janeiro 22291-090, Brazil; \\ eduardoneves@utfpr.edu.br \\ 9 Research Center in Sports Sciences, Health Sciences and Human Development (CIDESD), Trásos Montes and \\ Alto Douro University, 5001-801 Vila Real, Portugal; victormachadoreis@gmail.com \\ * Correspondence: dihogo.dematos@mail.mcgill.ca or dihogogmc@hotmail.com
}

Received: 16 September 2020; Accepted: 24 October 2020; Published: 31 October 2020

\begin{abstract}
To reduce transmission of the coronavirus, the Brazilian government adopted containment measures to control the virus' spread, including limitations to the practice of physical activity. It was aimed to analyze the effects of COVID-19 quarantine on physical activity levels, energy expenditure, quality of life, and level of stress in a sample of the Brazilian population. The sample included 426 participants (7 to 80 years). The International Physical Activity Questionnaire, Short form survey-36 (SF-36), and Stress Perception Scale, were used to assess the level of physical activity, quality of life and stress, respectively. The anthropometric data was used to the assessment of body mass index and basal metabolic rate. Body weight increased significantly in all sample $(p<0.05)$. During the pandemic, $84 \%$ of the sample indicated a low level of physical activity. Furthermore, weekly energy expenditure decreased significantly in all age groups during the pandemic (children $p<0.0001$; adolescents: $p<0.0001$; adults $p<0.001$, and elderly $p<0.0001$ ). All aspects of quality of life, significantly reduced in both sexes in all age groups $(p<0.05)$. With the exception of children, stress levels increased significantly during the pandemic (adolescents: male: $p=0.003$, female:
\end{abstract}


$p<0.05$; adults: male: $p=0.003$, female: $p=0.01$, and elderly: male: $p=0.02$, female: $p=0.03$ ). Findings from the present study suggests that COVID-19 social isolation has negatively affected Brazilian' physical activity and quality of life.

Keywords: COVID-19; physical activity; quality of life; stress; public health

\section{Introduction}

The Chinese Health Authority, on 31 December 2019, alerted the World Health Organization (WHO) to several cases of pneumonia of unknown etiology in Wuhan City, Hubei Province, Central China [1]. This pathogen was referred to as severe acute respiratory syndrome coronavirus 2 (SARS-CoV-2) in the coronavirus Research Group [2] and the disease was referred to as coronavirus disease 2019 (COVID-19) by WHO [1]. At the time of writing, more than 8 million people are infected worldwide resulting in more than 460 thousand deaths. In Brazil, there have been more than one million confirmed cases and more than 100 thousand deaths [1].

Owing to the rapid transmission of the virus and undocumented exposure, the WHO declared a public health emergency due to the lack of effective preventive or therapeutic medical treatments for COVID-19 infection [1]. In order to reduce the rate of transmission, countries have begun to adopt preventive measures recommended by the WHO including social distancing. Though successful in preventing outbreaks, strict exclusion interventions can adversely affect both physical and mental health, for example emerging adults rely on supportive peer experiences for their overall well-being [3]. Therefore, social distancing may have adverse effects with behavioral and clinical consequences.

Social isolation has been previously shown to be associated with both a decrease in physical activity levels and an increase in inactive behavior [4]. Fitbit, Inc. has recently shown data on physical activity before and during COVID-19 from 30 million users demonstrating a decline in steps, in the European population, ranging from 7\% to 38\% over the weekend of 22 March 2020 compared to the same period last year [5]. Preliminary evidence shows that social distancing has caused a significant decrease in physical activity levels in other confined conditions [6]. Some fields of study, such as epidemiology, indicate that a decline in physical activity as a consequence of a pandemic may have a negative effect on cardiovascular and mental health $[4,7]$.

In this context, it is known that physical inactivity causes more than 5 million deaths worldwide and that it is extremely harmful to the economy of public health systems [8]. For these reasons, government officials should encourage physical activity to promote health and prevent disease [8]. A standardized instrument used to assess levels of physical activity in a population, with a recall effect ("last 7 days" or "usual week"), is the International Physical Activity Questionnaire (IPAQ) [9]. This questionnaire allows to measure the following four intensity levels of physical activity: vigorous; moderate; walking; sitting [9]. Furthermore, from the IPAQ data on the time expended by each physical activity rate, it is possible to measure the levels of physical activity exercise and the corresponding weekly energy expenditure using the respective metabolic equivalent task (MET) of each physical activity [10].

In addition, social distancing has significant and negative implications for mental health including for example severe stress conditions, irritability, depression and depressive symptoms, mood disturbances, apprehension and panic, and anger [11]. Other quarantine-related stressors may include irregular or less frequent supplies, such as food items and medicines, and restrictions on routine daily activities [11]. Consequently, the noticeable decline in physical activity and social contact caused by safety measures may have serious long-term consequences for public health.

Therefore, the aim of this study was to analyze the effects of COVID-19 social distancing on physical activity and stress levels and quality of life in Brazil as well as evaluate the levels of physical activity expressed as energy expenditure (MET-minutes/week) before and during social distancing. 


\section{Methods}

The present study employed a cross-sectional online survey using the Google Forms web survey platform (Google LLC, Mountain View, CA, USA). The announcement, which included the link to the online survey, was sent by email as well as disseminated via social media such as Facebook, Instagram and WhatsApp, and shared with the personal contacts of the research group members.

All participants signed an online consent form accepting to participate in the present study. Regarding the sample of children and adolescents, at first the legal guardians were contacted through social media, and after the approval of the online term, the subjects received the link to the study. Those responsible for the children were instructed to follow and assist the entire process of answering and sending the questionnaire.

All participants were informed about the specific objective of the study before proceeding to the questionnaire. Participants were able to complete the survey only once and could terminate the survey at any time they desired. Ethical approval was awarded by The Ethics Committees of the Federal University of Rio Grande do Norte (Opinion: 3.996.317) according to Resolution 466/12 of the National Health Council, strictly respecting the ethical principles contained in the declaration of Helsinki.

\section{Sample}

Initially, 2000 subjects were invited to participate in the research and 1535 responded that they would accept to participate in the research. However, 454 presented the signed consent form (children and adolescents presented the consent of legal guardians). At the end, after removing duplicate and or incomplete responses, 426 responses were readable for the final analysis (Figure 1).

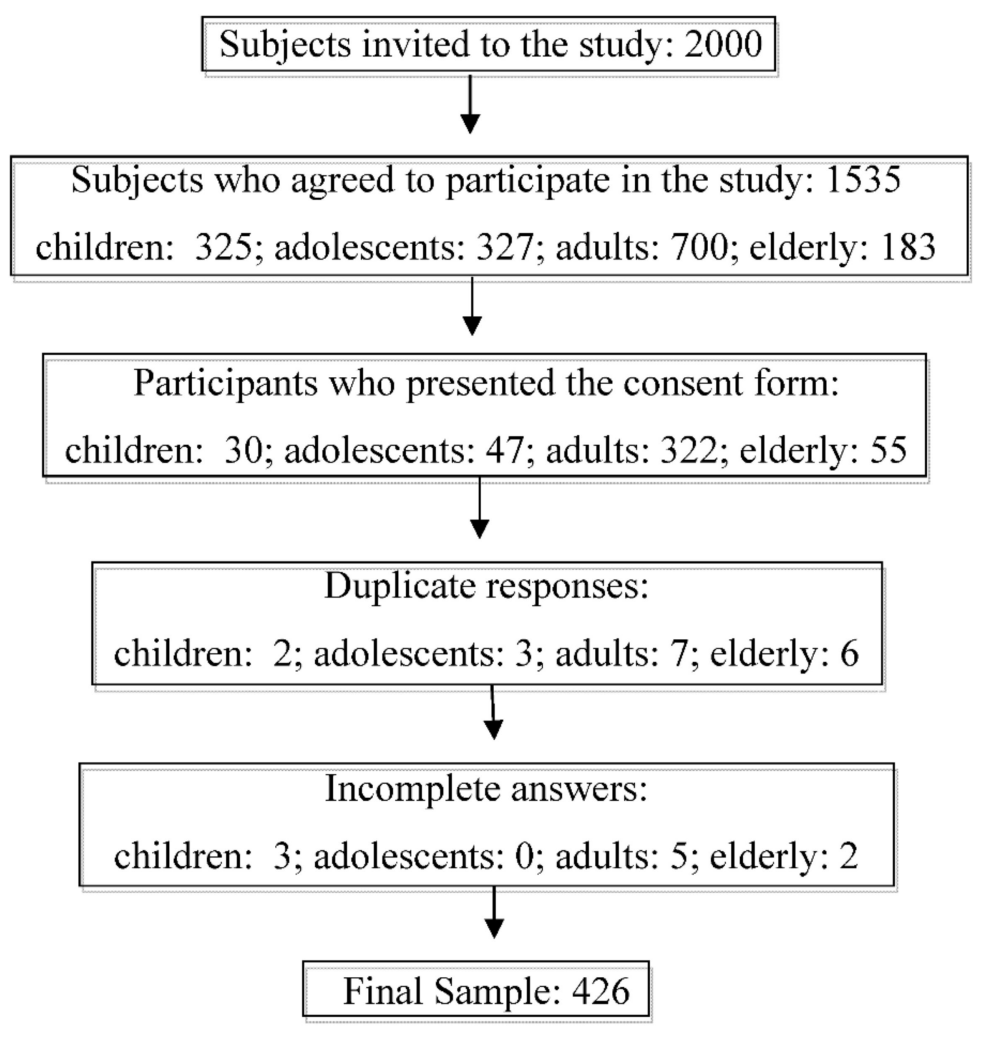

Figure 1. Sample recruitment.

The final sample was composed by 426 participants. The classification of age groups was defined based on the recommendations of Nithyashri and Kulanthaivel [12]. The sample was divided into the following groups: (i) children (age: $9.56 \pm 1.47 ; 60 \%$ male and $40 \%$ female), (ii) adolescents (age: 
$16.3 \pm 1.67 ; 43 \%$ male and 57\% female), (iii) Adults (age: $36.5 \pm 11.4 ; 49 \%$ male and $51 \%$ female), (iv) elderly (age: $66.3 \pm 5.07 ; 69 \%$ male and $31 \%$ female).

Participants completed the online questionnaire between the 12th of June (three months after the beginning of social isolation) and 12th of July 2020. Participants were recruited during the COVID-19 quarantine in Brazil, a period in which the measures taken by the government have limited the access to physical activity practices in all gyms, sports centers, and swimming pools.

To minimize the risk of error, data were cleaned by: removing of ineligible cases and multiple submissions from the same participant and identification and handling of irrelevant data. The latter were deemed invalid responses to the questionnaire, due to the lack of internal consistency of responses.

\section{Questionnaire}

The questionnaire was divided into four sections which included: (1) anthropometric data; (2) physical activity; quality of life; stress perception before the pandemic of COVID-19; (3) anthropometric data; (4) physical activity; quality of life; stress perception during the pandemic of COVID-19. Initially, through self-recall, the participants answered the questionnaires related to the pre-pandemic period. Then, questionnaires were related to the period during the pandemic.

\section{International Physical Activity Questionnaire (IPAQ)}

The level of physical activity was analyzed by the International Physical Activity Questionnaire (IPAQ), a tool previously validated for Brazilians $[13,14]$. The questionnaire contained questions related to physical activities performed in the last week prior to the application of the questionnaire. The questionnaire was structured and comprised questions regarding the frequency and duration of physical activities [9]. It attempts to recall physical activity that was performed for at least $10 \mathrm{~min}$ at a time. Three characteristics of the physical activity were evaluated a) intensity of the activity (mild, moderate or vigorous), frequency (days/week), and duration (time/day). The individuals were classified as inactive ( $<600$ MET-minutes/week), moderate active ( $\geq 600$ MET-minutes/week), and high active ( $\geq 3000$ MET-minutes/week) (http://www.ipaq.ki.se).

The weekly activity is recorded in METs (metabolic equivalent of task). The reference METs value used for calculation is: Walking - 3.3 METs; Moderate physical activity—4 METs; Vigorous physical activity -8 METs; the final value was derived by multiplying these reference values with the time (minutes) performed in a day and the numbers of days performed in a week.

Total MET $-\mathrm{min} /$ week $=$ MET - min $=$ week walking

MET - min $=$ week moderate physical activity

MET - min $=$ week vigorous physical activity

Based on the scores, participants were classified as (a) Inactive $-<600$ MET-min/week, (b) Insufficiently active $-\geq 600$ and $<3000 \mathrm{met}-\mathrm{min} /$ week, and (c) Active $\longrightarrow 23000$ MET-min/week.

\section{Short form Survey-36 (SF-36)}

The SF-36 is a validated questionnaire for the Brazilian population (all age groups) that measures the subjects' self-reported opinion about their physical and mental well-being [15-17]. It has eight domains of health-related quality of life (HRQOL): general health, physical functioning, role limitations due to physical health, energy/vitality, body pain, emotional well-being, role limitations due to emotional problems, and social functioning. Responses to each question within a domain are combined to generate a score from 0 to 100 , where 100 indicates "good health."

\section{Stress Perception Scale}

The Stress Perception Scale (EPS-10) is a instrument used to assess the perception of stress. Developed by Cohen et al. [18], it is a global assessment measure, which can be self-reported, allowing one to analyze how the individual's life situations are perceived as stressful factors. Each item is evaluated on a 5-point Likert scale, which ranges from zero (never) to 4 (very frequent). Of the ten 
items, six deal with negative aspects and four with positive aspects. To obtain the final score of the evaluation, the positive items (four) must be inversely scored, and then all items must be summed. Scores can range from zero to 40 , and the higher the score, the greater the perception of stress.

\section{Basal Metabolic Rate (BMR)}

To find the BMR values, the predictive equations proposed by Harris Benedict [19], were used:

$$
\begin{aligned}
& \text { BMR - Male: } 066.47+(13.751 * \text { body weight }(\mathrm{kg}))+(5.003 * \text { height }(\mathrm{cm}))-(6.755 * \text { age }(\text { years })) \\
& \text { BMR - Female: } 655.09+(9.563 * \text { body weight }(\mathrm{kg}))+(1.850 * \text { height }(\mathrm{cm}))-(4.676 * \text { age }(\text { years }))
\end{aligned}
$$

\section{Analyses}

The normality of the data was verified by the Kolmogorov-Smirnov and Z-scores for asymmetry and kurtosis ( -1.96 to 1.96). Bonferroni's correction was applied before all comparative analyzes. Comparison analyzes (between pandemic periods) were performed using the Student-dependent $t$ test. The effect size was verified by the Cohen test (d), the magnitude adopted was insignificant: $<0.19$; small: $0.20-0.49$; average: 0.50-0.79; large: 0.80-1.29; very large: $<1.30$ [20]. All analyses were performed using open source software R (version 4.0.1; R Foundation for Statistical Computing ${ }^{\circledR}$, Vienna, Austria) using an alpha level of $p<0.05$.

The sample power was subsequently determined based on the results obtained in the present study, considering: (1) age group and (2) sex. A standard of $\alpha=0.05$ and an $\beta=0.80$ was used [21]. These analyzes were performed using the open source software $G{ }^{*}$ Power $^{\circledR}$ (version 3.0; Berlin, Germany).

\section{Results}

Table 1 shows the sample characterization data in the pre and during social isolation conditions due to the quarantine of COVID-19. It was observed in all age groups and in both sexes that body weight increased significantly. BMI increased significantly in children, adolescents and adult males. It stands out for the groups analyzed that the sample power was: children of both sexes = between 0.62 and 0.70 (moderate to strong), adolescents of both sexes = between 0.70 and 0.75 (strong), adults of both sexes = between 0.74 and 0.83 (strong) and elderly men and women between 0.67 and 0.77 (moderate to strong).

It was observed that, in relation to the level of physical activity in the total sample: $4 \%$ of the subjects were inactive, $48 \%$ moderate active and $48 \%$ high active in the pre-pandemic period. While in the pandemic period, $84 \%$ of the sample was considered inactive, $13 \%$ moderate active, and $3 \%$ high active. Figure 2 reports the weekly energy expenditure in the sample, segmented by age groups. Thus, in relation to the periods before and during the pandemic, it was observed that: in children (male: ES: 3.02, C195\%: [1.93; 4.12], $p<0.0001$; female: ES: 3.26, C195\%: [1.82; 4.69], $p<0.0001$ ), in adolescents (male: ES: 4.25, CI 95\%: [3.06; 5.44], $p<0.0001$; female: ES: 4.01, CI 95\%: [3.02; 5.00]; $p<0.0001$ ), in adults (male: ES: 2.42, CI 95\%: [2.12; 2.72], $p<0.0001$; female: ES: 1.90, CI 95\%: [1.64; 2.17], $p<0.0001)$, and in the elderly (male: ES: 3.53, CI 95\%: [2.73; 4.33], $p<0.0001$; female: ES: 3.77, CI 95\%: [2.52; 5.02], $p<0.0001$ ) the weekly energy expenditure reduced significantly. 
Table 1. Sample Characterization.

\begin{tabular}{|c|c|c|c|c|}
\hline Variables & \multicolumn{2}{|c|}{ Children's } & \multicolumn{2}{|c|}{ Adolescents } \\
\hline Sample $\left(\mathrm{N}^{\circ}(\%)\right)$ & \multicolumn{2}{|c|}{$25(100 \%)$} & \multicolumn{2}{|c|}{$44(100 \%)$} \\
\hline Female $\left(\mathrm{N}^{\circ}(\%)\right)$ & \multicolumn{2}{|c|}{$10(40 \%)$} & \multicolumn{2}{|c|}{$25(57 \%)$} \\
\hline Male $\left(\mathrm{N}^{\circ}(\%)\right)$ & \multicolumn{2}{|c|}{$15(60 \%)$} & \multicolumn{2}{|c|}{$19(43 \%)$} \\
\hline Age (Yrs) & \multicolumn{2}{|c|}{$9.56 \pm 1.47$} & \multicolumn{2}{|c|}{$16.3 \pm 1.67$} \\
\hline \multirow[t]{4}{*}{ Stature $(\mathrm{cm})$} & \multicolumn{2}{|c|}{$138.0 \pm 8.18$} & \multicolumn{2}{|c|}{$159.8 \pm 13.7$} \\
\hline & \multicolumn{2}{|c|}{ Male } & \multicolumn{2}{|c|}{ Male } \\
\hline & \multicolumn{4}{|c|}{ Pandemic Moments } \\
\hline & Pré & During & Pré & During \\
\hline Weight (Kg) & $34.0 \pm 9.18$ & $* 38.8 \pm 8.61$ & $52.6 \pm 15.8$ & *58.4 \pm 15.5 \\
\hline $\operatorname{BMI}\left(\mathrm{kg} / \mathrm{m}^{2}\right)$ & $18.5 \pm 7.00$ & $* 21.2 \pm 7.10$ & $21.2 \pm 3.45$ & $23.6 \pm 2.97$ \\
\hline \multirow[t]{2}{*}{ BMR (Kcal) } & $1328.4 \pm 326.0$ & $1384.5 \pm 302.3$ & $1430.5 \pm 265.3$ & $1497.9 \pm 252.6$ \\
\hline & \multicolumn{2}{|c|}{ Female } & \multicolumn{2}{|c|}{ Female } \\
\hline Weight (Kg) & $32.0 \pm 5.79$ & $* 36.2 \pm 4.34$ & $60.4 \pm 15.0$ & ${ }^{*} 65.8 \pm 14.0$ \\
\hline $\operatorname{BMI}\left(\mathrm{kg} / \mathrm{m}^{2}\right)$ & $16.5 \pm 3.52$ & $18.7 \pm 3.13$ & $22.4 \pm 3.72$ & $24.4 \pm 3.05$ \\
\hline \multirow[t]{2}{*}{ BMR (Kcal) } & $1167.6 \pm 54.6$ & $1207.5 \pm 39.0$ & $1450.9 \pm 158.9$ & $1502.3 \pm 150.4$ \\
\hline & \multicolumn{2}{|c|}{ Adults } & \multicolumn{2}{|c|}{ Elderly } \\
\hline Sample $\left(\mathrm{N}^{\circ}(\%)\right)$ & \multicolumn{2}{|c|}{$310(100 \%)$} & \multicolumn{2}{|c|}{$47(100 \%)$} \\
\hline Female $\left(\mathrm{N}^{\circ}(\%)\right)$ & \multicolumn{2}{|c|}{$159(51 \%)$} & \multicolumn{2}{|c|}{$15(31 \%)$} \\
\hline Male $\left(\mathrm{N}^{\circ}(\%)\right)$ & \multicolumn{2}{|c|}{$151(49 \%)$} & \multicolumn{2}{|c|}{$32(69 \%)$} \\
\hline Age (Yrs) & \multicolumn{2}{|c|}{$36.5 \pm 11.4$} & \multicolumn{2}{|c|}{$66.3 \pm 5.07$} \\
\hline \multirow[t]{2}{*}{ Stature $(\mathrm{cm})$} & \multicolumn{2}{|c|}{$164.4 \pm 12.7$} & 174. & 8.91 \\
\hline & & & & \\
\hline Weight $(\mathrm{Kg})$ & $67.9 \pm 18.1$ & $* 72.3 \pm 17.4$ & $79.0 \pm 9.68$ & *83.7 \pm 9.06 \\
\hline $\operatorname{BMI}\left(\mathrm{kg} / \mathrm{m}^{2}\right)$ & $24.1 \pm 3.72$ & *26.9 \pm 8.23 & $25.7 \pm 2.59$ & $27.3 \pm 0.54$ \\
\hline BMR (Kcal) & $1550.7 \pm 294.8$ & $1614.9 \pm 275.6$ & $1588.5 \pm 239.0$ & $1654.9 \pm 248.1$ \\
\hline & & & & \\
\hline Weight (Kg) & $64.6 \pm 13.9$ & ${ }^{*} 68.1 \pm 13.8$ & $77.6 \pm 7.72$ & *81.9 \pm 7.88 \\
\hline $\operatorname{BMI}\left(\mathrm{kg} / \mathrm{m}^{2}\right)$ & $24.1 \pm 3.58$ & $25.6 \pm 3.57$ & $28.2 \pm 2.63$ & $27.6 \pm 2.19$ \\
\hline BMR (Kcal) & $1394.6 \pm 139.5$ & $1428.6 \pm 139.9$ & $1391.1 \pm 81.4$ & $1432.7 \pm 88.9$ \\
\hline
\end{tabular}

${ }^{*} p<0.0001$. BMI $=$ Body Mass Index. BMR $=$ Basal Metabolic Rate. $\mathrm{M}=$ Male. $\mathrm{F}=$ Female.

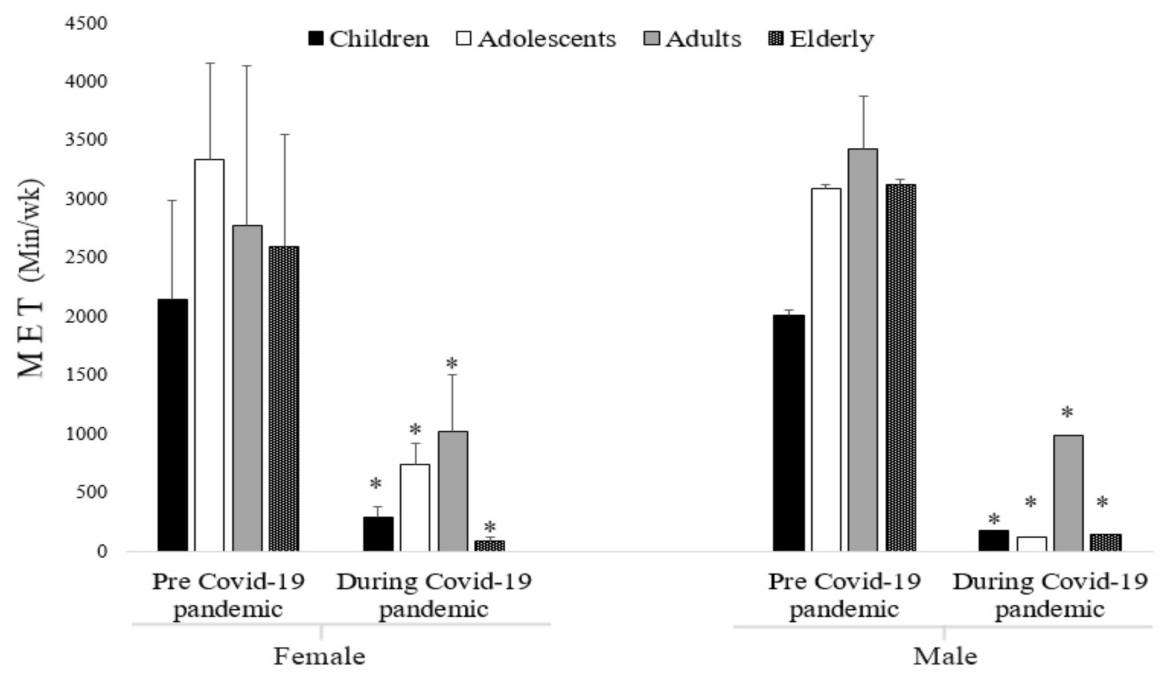

Figure 2. Weekly energy expenditure. * Statistically significant.

Table 2 is stratified by age, the results referring to aspects of quality of life in the pre- and during social isolation conditions of the COVID-19 pandemic. There was a significant decrease in all aspects of quality of life analyzed by the SF-36 in all age groups analyzed, with the exception of the vitality aspect in female subjects in the elderly group that did not show any difference between the periods analyzed. 
Table 2. Quality of life analysis.

\begin{tabular}{|c|c|c|c|c|}
\hline Domain-Raw Scale & \multicolumn{2}{|c|}{ Children's } & \multicolumn{2}{|c|}{ Adolescents } \\
\hline & \multicolumn{4}{|c|}{ Pandemic Moments } \\
\hline & \multicolumn{2}{|c|}{ Male } & \multicolumn{2}{|c|}{ Male } \\
\hline & Pre & During & Pre & During \\
\hline FC & $90.33 \pm 5.81$ & $* 30.9 \pm 21.6$ & $91.3 \pm 3.26$ & $* 24.2 \pm 8.10$ \\
\hline LPA & $96.6 \pm 12.9$ & $* 6.45 \pm 1.66$ & $100.0 \pm 0.00$ & ${ }^{*} 0.00 \pm 0.00$ \\
\hline Pain & $76.5 \pm 30.6$ & $* 38.3 \pm 46.1$ & $78.9 \pm 27.9$ & $* 40.8 \pm 24.3$ \\
\hline GHS & $61.2 \pm 8.96$ & $* 49.8 \pm 12.5$ & $66.4 \pm 17.5$ & $* 50.7 \pm 14.2$ \\
\hline VIT & $66.0 \pm 17.7$ & $* 47.0 \pm 19.3$ & $62.6 \pm 18.0$ & $* 40.5 \pm 16.1$ \\
\hline AS & $57.5 \pm 28.2$ & $* 32.8 \pm 18.3$ & $75.0 \pm 28.8$ & $* 28.2 \pm 13.5$ \\
\hline EA & $97.7 \pm 8.60$ & $* 8.60 \pm 2.22$ & $94.7 \pm 16.7$ & $* 15.2 \pm 3.50$ \\
\hline \multirow[t]{2}{*}{$\mathrm{MH}$} & $68.2 \pm 14.7$ & $* 33.0 \pm 23.0$ & $68.2 \pm 17.7$ & $* 35.3 \pm 15.8$ \\
\hline & \multicolumn{2}{|c|}{ Female } & \multicolumn{2}{|c|}{ Female } \\
\hline FC & $79.0 \pm 9.36$ & $* 28.0 \pm 14.6$ & $86.2 \pm 22.5$ & $* 25.8 \pm 9.90$ \\
\hline LPA & $95.0 \pm 15.8$ & $* 0.00 \pm 0.00$ & $100.0 \pm 0.00$ & $* 27.6 \pm 8.00$ \\
\hline Pain & $65.9 \pm 21.2$ & $54.2 \pm 20.0$ & $77.0 \pm 35.8$ & $* 21.6 \pm 9.80$ \\
\hline GHS & $69.1 \pm 55.9$ & $* 69.1 \pm 14.7$ & $68.3 \pm 12.8$ & $* 47.4 \pm 10.6$ \\
\hline VIT & $56.5 \pm 18.4$ & $56.5 \pm 12.2$ & $63.2 \pm 20.5$ & $* 35.8 \pm 11.1$ \\
\hline AS & $56.2 \pm 14.7$ & $48.7 \pm 16.0$ & $75.0 \pm 35.1$ & $* 25.0 \pm 9.00$ \\
\hline EA & $96.6 \pm 10.5$ & *21.0 \pm 6.66 & $97.33 \pm 9.22$ & $* 15.7 \pm 5.33$ \\
\hline \multirow[t]{3}{*}{$\mathrm{MH}$} & $60.8 \pm 15.1$ & $* 40.4 \pm 11.8$ & $67.5 \pm 16.7$ & $* 21.6 \pm 6.30$ \\
\hline & \multicolumn{2}{|c|}{ Adults } & \multicolumn{2}{|c|}{ Elderly } \\
\hline & \multicolumn{2}{|c|}{ Male } & \multicolumn{2}{|c|}{ Male } \\
\hline FC & $89.6 \pm 10.0$ & $* 29.6 \pm 5.19$ & $86.2 \pm 10.7$ & $* 17.1 \pm 7.96$ \\
\hline LPA & $94.3 \pm 18.5$ & $* 18.2 \pm 5.62$ & $97.6 \pm 13.2$ & $* 4.41 \pm 0.78$ \\
\hline Pain & $73.3 \pm 25.3$ & $* 49.4 \pm 9.34$ & $79.5 \pm 25.2$ & $* 33.2 \pm 1.06$ \\
\hline GHS & $63.5 \pm 16.1$ & $* 55.11 \pm 18.7$ & $63.6 \pm 15.3$ & $* 53.6 \pm 10.4$ \\
\hline VIT & $55.5 \pm 20.2$ & $* 46.5 \pm 15.7$ & $58.1 \pm 21.0$ & $* 40.3 \pm 18.0$ \\
\hline AS & $66.6 \pm 32.4$ & $* 36.3 \pm 9.37$ & $64.4 \pm 32.5$ & $* 28.9 \pm 7.39$ \\
\hline EA & $89.1 \pm 23.2$ & ${ }^{*} 19.2 \pm 6.62$ & $94.7 \pm 19.1$ & $* 8.19 \pm 2.08$ \\
\hline \multirow[t]{2}{*}{$\mathrm{MH}$} & $65.0 \pm 14.5$ & $* 36.4 \pm 3.26$ & $67.2 \pm 13.2$ & $25.0 \pm 6.31$ \\
\hline & \multicolumn{2}{|c|}{ Female } & \multicolumn{2}{|c|}{ Female } \\
\hline FC & $86.3 \pm 15.1$ & $* 31.1 \pm 3.23$ & $82.6 \pm 21.1$ & $* 29.1 \pm 19.6$ \\
\hline LPA & $90.8 \pm 23.6$ & $* 26.3 \pm 12.1$ & $93.3 \pm 25.8$ & $* 6.45 \pm 166$ \\
\hline Pain & $75.6 \pm 25.8$ & $* 49.5 \pm 9.97$ & $67.2 \pm 23.8$ & $* 48.2 \pm 5.66$ \\
\hline GHS & $63.3 \pm 16.5$ & $* 57.4 \pm 17.1$ & $56.8 \pm 14.2$ & $* 43.2 \pm 10.0$ \\
\hline VIT & $56.4 \pm 19.3$ & $* 47.1 \pm 16.5$ & $49.0 \pm 19.8$ & $48.0 \pm 20.4$ \\
\hline AS & $67.3 \pm 33.0$ & $* 38.2 \pm 3.81$ & $61.6 \pm 31.1$ & $* 25.0 \pm 7.54$ \\
\hline EA & $87.4 \pm 22.7$ & $* 27.6 \pm 14.2$ & $95.5 \pm 11.7$ & ${ }^{*} 0.00 \pm 0.00$ \\
\hline MH & $65.4 \pm 13.8$ & ${ }^{*} 40.4 \pm 16.22$ & $60.2 \pm 19.4$ & $* 33.3 \pm 13.8$ \\
\hline
\end{tabular}

$* p<0.0001$. FC $=$ Functional Capacity. LPA $=$ Limitation by physical aspect. GHS $=$ General Health Status. VIT $=$ Vitality. $\mathrm{SA}=$ Social Aspects. $\mathrm{EA}=$ Emotional Aspects. $\mathrm{MH}=$ Mental Health. $\mathrm{M}=$ Male. $\mathrm{F}=$ Female.

Figure 3 shows graphically the data regarding the perceived stress scale in different age groups. 


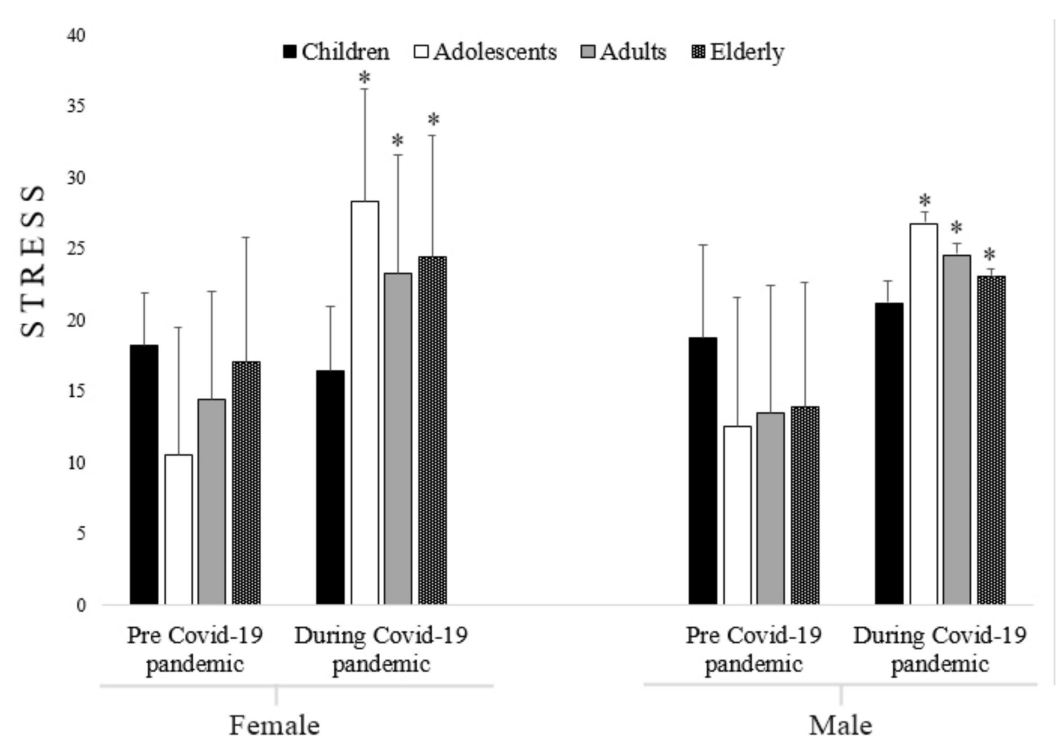

Figure 3. Perceived Stress Scale analysis. ${ }^{*}$ Statistically significant.

It was observed that, in relation to the periods before and during the pandemic, there were no significant differences in children (male: ES: 0.40 , CI 95\%: [-0.35; 1.15]; $p=0.3$; female: ES: $0.44,95 \%$ CI: [-0.51; 1.39], $p>0.05$ ). While in adolescents (male: ES: 1.49, CI 95\%: [0.75; 2.24]; $p=0.003$; female: ES: 2.11, CI 95\%: [1.40; 2.82]; $p<0.05$ ), adults (male: ES: 1.18, 95\% CI: [0.94; 1.43]; $p=0.003$; female: ES: 1.10, 95\% CI: [0.86; 1.33], $p=0.01$ ), and the elderly (male: ES: 1.16, 95\% CI: [0.62; 1.70], $p=0.02$; female: ES: 0.85, CI 95\%: $[0.07 ; 1.63], p=0.03)$ stress levels increased from significantly.

\section{Discussion}

The present study aimed to analyze the effects of COVID-19 quarantine on physical activity levels and mental health in a sample of the Brazilian population as well as evaluate the levels of physical activity expressed as energy expenditure (MET-minutes/week) before and during the social isolation. It is important to note that the results were based on a survey in which respondents had to recall their status before the pandemic. The main results were: (1) The responders reported that their weight was higher during the pandemic compared to before the pandemic. (2) Weekly energy expenditure has largely decreased in the period during the pandemic compared to the pre-pandemic period. (3) The number of subjects who were categorized as inactive in the period during the pandemic increased from $4 \%$ to $84 \%$ in relation to the pre pandemic period (4). The responders reported lower quality of life in all age groups during the pandemic. (5) Adolescents, adults and the elderly showed greater perceived stress during the pandemic.

Notably, due to the fact of social isolation and the measures taken by the Brazilian government in order to control the spread of COVID-19, the results of the present research show an increase in body weight, BMI, reduction of energy expenditure and level of physical activity in the evaluated group. The COVID-19 pandemic has created a situation that induces decreased levels of routine physical activity due to self-isolation and quarantine conditions, limited opportunity to stay physically active and reduced risk of infection. Due to this fact, Costa et al. [22] showed that during the pandemic, the level of physical activity of Brazilians reduced significantly, becoming harmful to the health of the population. Sustained physical inactivity is usually associated with decreased physical and mental wellbeing and elevated disease-specific behavior and all-cause mortality risk [23].

Despite the preventive strategy to limit COVID-19 infections, social isolation may have unintended negative effects, causing the rise in occupational inactivity and emotional disorders of the population [24]. Social isolation can lead to a reduction in social contact and longer periods of immobility, directly or indirectly due to the increasing use of interactive devices, such as TV, computers and mobile phones [25]. 
In addition, physical inactivity is known to be a contributing factor for serious non-communicable conditions, such as coronary disorders, certain cancers and diabetes [26], some of the comorbidities linked with severe cases of acute respiratory syndrome attributed to COVID-19 [2] and significant causes of death worldwide [27].

The creation of alternative methodologies that encourage people's autonomy and facilitate the awareness and preservation of physical activity is therefore necessary for health promotion, disease prevention and control [28]. Physical activity provides advantages that are related to the experience of its practice and can have immediate and long-term impacts on wellbeing [4]. In fact, it will reduce the adverse effects of long periods of immobility and improve the immune response to infections [23]. It has a significant effect on the severity of complications and the quality of the clinical image in people with COVID-19 or other communicable diseases [29].

It is noteworthy that the levels of quality of life significantly decreased in children, adolescents, adults and the elderly of both sexes. It is known that the emotional aspect of quality of life is influenced by external factors such as socialization and environmental well-being [30]. In this context, external factors are interpreted intrinsically by the subjects' physiological response and reflect on positive or negative sensations that significantly affect the human body in relation to the enhancement of health or its fall [31].

In this context, social isolation can enhance of loneliness and abandonment, which trigger adverse behavioral relationships (i.e., aggressiveness, crying, emotional pain, etc.) [32,33]. Moreover, the absence of social interaction can affect the emotional perception that will influence the feeling of vitality and the perception of general health. This has a direct influence mental health, and all these interconnected reactions can be harmful to the physical aspects, which can reduce functionality and increase the perception of physical pain [33,34].Therefore, the self-perceived quality of life tends to suffer negative changes during the isolation period of the COVID-19 pandemic $[29,30]$. This current scenario can bring complications to public health at regional, national and global scales $[35,36]$.

Regarding perceived stress, the present study found that there was an increase in the adolescent, adult and elderly groups during the pandemic. Bezerra et al. [37], identified that during social isolation due to COVID-19, Brazilians of different age groups, showed a significant increase in the level of stress. Periods of isolation and deprivation away from day-to-day life, decreased exposure to everyday needs/finance, a sense of vulnerability mixed with fear of contagion, as well as potential information overload can all contribute to negative emotions and anxiety [38]. During this time of physical and social constraints, people reported high rates of severe hostility, depression, insomnia and anxiety [39].

Online networking is one of the key platforms for updating COVID-19 knowledge, as $82.0 \%$ of the participants in a study were consistently exposed to social media [40]. Nevertheless, access to mass media can lead to "infodemic," which relates to too much confusing information that contributes to people's difficulties in seeking credible sources of information, and can also harm people's physical and mental health [41].

Kowal et al. [42], analyzed more than 50 thousand people of both sexes from 27 different countries and pointed out that the levels of stress during the COVID-19 pandemic are influenced by the age group, especially the younger ones. In addition, the aforementioned authors also showed that female subjects indicated higher levels of stress due to being single, staying with one or more children, and living in collectivistic cultures [42]. It is worth mentioning that, although the authors did not analyze Brazilian people, the present research found similar results in relation to the increase in perceived stress in adolescents, adults and the elderly.

The solution to the COVID-19 outbreak has raised social isolation in unprecedented proportions on a global scale. Although these steps are critical to mitigating disease spread, attention must be paid to future disruption and to alleviating the effect of social isolation on public health. 


\section{Mitigation Strategies to Keep Active}

Home physical activity programs are known to be efficient, low cost, and when applied in a structured way, they facilitate improvements in health-related physical activity aspects, based on the physical condition of each person $[43,44]$. It is also a promising and successful approach to growing and sustaining population rates of physical activity and immune response to COVID-19 to be implemented as a public health strategy. Therefore, some strategies should also be implemented in order to remain active in according to standards of American College of Sports Medicine [45].

\section{Children and Adolescents}

Children and adolescents must be able to perform physical activity of mild to intense strength, or to play for $60 \mathrm{~min}$ a day, as time and space permit. For instance, jumping rope is an aerobic exercise, which often strengthens bones and muscles. Another strategy is to include the whole family in a game with them (like Nintendo Wii ${ }^{\circledR}$ ), helping to promote contact and social participation. It may help to reduce levels of stress and enhance the quality of life. In children and adolescents who were not involved previous to the COVID-19 pandemic, it is recommended to continue moderate intensity exercise every day for 10 to $15 \mathrm{~min}$. If necessary, seek guidance from a fitness professional (personal trainer) on the progress of exercise [45].

\section{Adults and Elderly}

It can be advised that adults engage in physical exercise for a minimum of 150 min a week of aerobic physical activity with moderate intensity or fewer than 75 min with aerobic physical activity with intense physical ability 2-3h a week in body strength training (e.g., yoga, dumbbells, resistance bands) [45]. Elderly people are advised to follow the same physical activity advice as younger adults. Elderly people who are not active should be advised to practice light activities to avoid the inactive compartment (e.g., sitting and getting up from the chair, lifting food packages) [45].

However, despite the relevance of the results, the present study has some limitations: (1) The sample number was relatively low and may not have been a good estimator of the general population. (2) The assessment of the pre-pandemic questionnaires was based on reports based on memories, which may have had an influence on the completion of the questionnaires.

\section{Conclusions}

We conclude that the current scenario of social isolation has negatively affected the level of physical activity, quality of life and stress level in Brazilians. In addition, implementing an adapted physical training program at home during the period of the pandemic, which may well extend from weeks to months, will decrease the negative physiological and psychological impact of inactive behaviors.

Author Contributions: Main Researcher, D.G.d.M., Conceptualization, F.J.A., P.F.d.A.-N., Formal analysis, O.C.M., R.F.d.S., A.C.M., Investigation, D.G.d.M., L.S.M.-B., F.d.A.M.J., L.F.L., J.L.d.S., Writing-original draft, I.G., A.d.A.C.e.S., E.B.N., Writing-review \& editing, B.G.d.A.T.C., V.M.R., A.N.-S. All authors have read and agreed to the published version of the manuscript.

Funding: This research received no external funding.

Acknowledgments: For your support and encouragement for the development of this academic article, we thank the National Council for Scientific Development (CNPQ) and the Higher Education Personnel Improvement Coordination (CAPES).

Conflicts of Interest: The authors declare no conflict of interest. 


\section{References}

1. World Health Organization (WHO). Coronavirus Disease 2019 (COVID-19) Situation Report-23; World Health Organization: Geneva, Switzerland, 2020.

2. Gorbalenya, A.E.; Baker, S.C.; Baric, R.; Groot, R.J.D.; Drosten, C.; Gulyaeva, A.A.; Penzar, D. Severe acute respiratory syndrome-related coronavirus: The species and its viruses-a statement of the Coronavirus Study Group. bioRxiv 2020, 10, 07-937862.

3. Hopmeyer, A.; Medovoy, T. Emerging adults' self-identified peer crowd affiliations, risk behavior, and social-emotional adjustment in college. Emerg. Adulthood 2017, 5, 143-148. [CrossRef]

4. Peçanha, T.; Goessler, K.F.; Roschel, H.; Gualano, B. Social isolation during the COVID-19 pandemic can increase physical inactivity and the global burden of cardiovascular disease. Am. J. Physiol. Heart Circ. Physiol. 2020, 318, H1441-H1446. [CrossRef] [PubMed]

5. Fitbit, Inc. The Impact of Coronavirus on Global Activity (Online). Available online: https://blog.fitbit.com/ covid-19-global-activity/ (accessed on 25 June 2020).

6. Belavý, D.L.; Gast, U.; Daumer, M.; Fomina, E.; Rawer, R.; Schießl, H.; Felsenberg, D. Progressive adaptation in physical activity and neuromuscular performance during 520d confinement. PLoS ONE 2013, 8, e60090. [CrossRef]

7. Herbolsheimer, F.; Ungar, N.; Peter, R. Why is social isolation among older adults associated with depressive symptoms? The mediating role of out-of-home physical activity. Int. J. Behav. Med. 2018, 25, 649-657. [CrossRef]

8. Lee, I.M.; Shiroma, E.J.; Lobelo, F.; Puska, P.; Blair, S.N.; Katzmarzyk, P.T. Lancet Physical Activity Series Working Group. Effect of physical inactivity on major non-communicable diseases worldwide: An analysis of burden of disease and life expectancy. Lancet 2012, 380, 219-229. [CrossRef]

9. Hallal, P.C.; Victora, C.G. Reliability and validity of the International Physical Activity Questionnaire (IPAQ). Med. Sci. Sports Exerc. 2004, 36, 556. [CrossRef]

10. Ainsworth, B.E.; Haskell, W.L.; Leon, A.S.; Jacobs, D.R., Jr.; Montoye, H.J.; Sallis, J.F.; Paffenbarger, R.S., Jr. Compendium of physical activities: Classification of energy costs of human physical activities. Med. Scie Sports Exer. 1993, 25, 71-80. [CrossRef] [PubMed]

11. Brooks, S.K.; Webster, R.K.; Smith, L.E.; Woodland, L.; Wessely, S.; Greenberg, N.; Rubin, G.J. The psychological impact of quarantine and how to reduce it: Rapid review of the evidence. Lancet 2020,395, 912-920. [CrossRef]

12. Nithyashri, J.; Kulanthaivel, G. Classification of human age based on Neural Network using FG-NET Aging database and Wavelets. In Proceedings of the 2012 Fourth International Conference on Advanced Computing (ICoAC), Chennai, India, 13-15 December 2012.

13. Matsudo, S.; Araújo, T.; Marsudo, V.; Andrade, D.; Andrade, E.; Braggion, G. International Physical Activity Questionnaire (IPAQ): Study of validity and reproducibility in Brazil. Braz. J. Phys. Act. Health (Rev Bras AtivFisSaúde) 2001, 6, 5-18.

14. de Souza, B.V.; Dias, R.; Correa, D.A. The use of the international physical activity questionnaire (IPAQ) as a diagnostic tool for the level of physical fitness: A review in Brazil. Saúde Rev. 2012, 12, 49-54.

15. Ciconelli, R.M.; Ferraz, M.B.; Santos, W.; Meinão, I.; Quaresma, M.R. Translation into Portuguese and validation of the generic SF-36 quality of life assessment questionnaire (Brazil SF-36). Rev. Bras. Reumatol. 1999, 39, 143-150.

16. Stanghelle, B.; Bentzen, H.; Giangregorio, L.; Pripp, A.H.; Skelton, D.; Bergland, A. Effects of a resistance and balance exercise programme on physical fitness, health-related quality of life and fear of falling in older women with osteoporosis and vertebral fracture: A randomized controlled trial. Osteoporos. Intern. 2020, 31, 1069-1078. [CrossRef]

17. Lopez-Nava, G.; Asokkumar, R.; Lacruz, T.; Rull, A.; Beltran, L.; Bautista-Castaño, I. The effect of weight loss and exercise on Health-Related Quality of Life (HRQOL) following Endoscopic Bariatric Therapies (EBT) for obesity. Health Q. Life Outcomes 2020, 18, 1-9.

18. Cohen, S.; Kamarck, T.; Mermelstein, R. A global measure of perceived stress. J. Health Soc. Behav. 1983, 24, 385-396. [CrossRef] [PubMed]

19. Harris, J.A.; Benedict, F.G. A biometric study of human basal metabolism. PNAS 1918, 4, 370. [CrossRef]

20. Espirito-Santo, H.; Daniel, F. Calculating and reporting effect sizes on scientific papers (1): $p<0.05$ limitations in the analysis of mean differences of two groups. Rev. Port. Investig. Comport. Soc. 2015, 1, 3-16. 
21. Faul, F.; Erdfelder, E.; Lang, A.-G.; Buchner, A. G*Power 3: A flexible statistical power analysis program for the social, behavioral, and biomedical sciences. Behav. Res. Methods 2007, 39, 175-191. [CrossRef]

22. Costa, C.L.A.; Costa, T.M.; Barbosa-Filho, V.C.; Bandeira, P.F.R.; Siqueira, R.C.L. Influência do distanciamento social no nível de atividade física durante a pandemia do COVID-19. Rev. Bras. Ativ. Fís. Saúde 2020, 25, 1-6. [CrossRef]

23. Pinto, A.J.; Dunstan, D.W.; Owen, N.; Bonfá, E.; Gualano, B. Combating physical inactivity during the COVID-19 pandemic. Nat. Rev. Rheumat. 2020, 16, 347-348. [CrossRef]

24. Reis, R.S.; Salvo, D.; Ogilvie, D.; Lambert, E.V.; Goenka, S.; Brownson, R.C. Lancet Physical Activity Series 2 Executive Committee. Scaling up physical activity interventions worldwide: Stepping up to larger and smarter approaches to get people moving. Lancet 2016, 388, 1337-1348. [CrossRef]

25. Brazendale, K.; Beets, M.W.; Weaver, R.G.; Pate, R.R.; Turner-McGrievy, G.M.; Kaczynski, A.T.; von Hippel, P.T. Understanding differences between summer vs. school obesogenic behaviors of children: The structured days hypothesis. Intern. J. Behav. Nut. Phys. Activ. 2017, 14, 100. [CrossRef] [PubMed]

26. Ekelund, U.; Steene-Johannessen, J.; Brown, W.J.; Fagerland, M.W.; Owen, N.; Powell, K.E. Lancet Sedentary Behaviour Working Group. Does physical activity attenuate, or even eliminate, the detrimental association of sitting time with mortality? A harmonised meta-analysis of data from more than 1 million men and women. Lancet 2016, 388, 1302-1310. [CrossRef]

27. World Health Organization. More Active People for a Healthier World: Global Action Plan on Physical Activity 2018-2030; World Health Organization: Geneva, Switzerland, 2018.

28. Wang, G.; Zhang, Y.; Zhao, J.; Zhang, J.; Jiang, F. Mitigate the effects of home confinement on children during the COVID-19 outbreak. Lancet 2020, 395, 945-947. [CrossRef]

29. Zhou, F.; Yu, T.; Du, R.; Fan, G.; Liu, Y.; Liu, Z.; Xiang, J.; Wang, Y.; Song, B.; Gu, X.; et al. Clinical course and risk factors for mortality of adult in patients with COVID-19 in Wuhan, China: A retrospective cohort study. Lancet 2020, 395, 1054-1062. [CrossRef]

30. Marković, B.; Arsovski, S. Emotional design and quality of life. Center Qual. 2007, 20, 141. [CrossRef]

31. Dubey, S.; Biswas, P.; Ghosh, R.; Chatterjee, S.; Dubey, M.J.; Chatterjee, S.; Lavie, C.J. Psychosocial impact of COVID-19. Diabetes Metab. Syndr. Clin. Res. Rev. 2020, 14, 779-788. [CrossRef]

32. Imran, N.; Zeshan, M.; Pervaiz, Z. Mental health considerations for children \& adolescents in COVID-19 Pandemic. Pakistan J. Med. Scie. 2020, 36. [CrossRef]

33. Li, S.; Wang, Y.; Xue, J.; Zhao, N.; Zhu, T. The impact of COVID-19 epidemic declaration on psychological consequences: A study on active Weibo users. Int. J. Environ. Res. Public Health 2020, 17, 2032. [CrossRef]

34. Schmidt, B.; Crepaldi, M.A.; Bolze, S.D.A.; Neiva-Silva, L.; Demenech, L.M. Impacts on Mental Health and Psychological Interventions Faced with the New Coronavirus Pandemic (COVID-19). Estudos Psicol. 2020, 37, 1-13.

35. Chwaszcz, J.; Palacz-Chrisidis, A.; Wiechetek, M.; Bartczuk, R.P.; Niewiadomska, I.; Sławska, P. Quality of life and its factors in the COVID19 pandemic situation. Results of Stage 1 studies during the pandemic growth period. arXiv 2020, arXiv:10.31234.

36. World Health Organization. Be Active during COVID-19; WHO: Geneva, Switzerland, 2020; Available online: https://www.who.int/news-room/q-a-detail/be-activeduring-covid-19 (accessed on 25 June 2020).

37. Bezerra, A.C.V. Factors associated with population behavior during social isolation in the COVID-19 pandemic. CiênciaSaúdeColetivo 2020, 25, 2411-2421.

38. Burtscher, J.; Burtscher, M.; Millet, G.P. (Indoor) isolation, stress and physical inactivity: Vicious circles accelerated by Covid-19? Scand. J. Med. Sci. Sports 2020. [CrossRef]

39. Haney, C.; Weill, J.; Bakhshay, S.; Lockett, T. Examining jail isolation. Prison J. 2015, 96, 126-152. [CrossRef]

40. Bao, Y.; Sun, Y.; Meng, S.; Shi, J.; Lu, L. 2019-nCoV epidemic: Address mental health care to empower society. Lancet 2020, 395, e37-e38. [CrossRef]

41. Cinelli, M.; Quattrociocchi, W.; Galeazzi, A.; Valensise, C.M.; Brugnoli, E.; Scala, A. The covid-19 social media infodemic. arXiv 2020, arXiv:2003.05004.

42. Kowal, M.; Coll-Martín, T.; Ikizer, G.; Rasmussen, J.; Eichel, K.; Studzinska, A.; Lieberoth, A. Who Is the Most Stressed During COVID-19 Isolation? Data from 27 Countries. 2020. [CrossRef]

43. Riebe, D.; Ehrman, J.K.; Liguori, G.; Magal, M. organizadores. ACSM's Guidelines for Exercise Testing and Prescription, 10th ed.; Wolters Kluwer: Philadelphia, PA, USA, 2018. 
44. Matias, G.H.L.; Guerra, A.C.; Souza Filho, B.A.B.; Lima, J.T.O.; Carmo, C.N.; Mattos, I.E. Repeatability and reproducibility of a home exercise manual. Fisioter. Pesq. 2018, 25, 209-216. [CrossRef]

45. American College of Sports Medicine (ACSM). Staying Active during the Coronavirus Pandemic. 2020. Available online: https://www.exerciseismedicine.org/assets/page_documents/EIM_Rx\% (accessed on 16 September 2020).

Publisher's Note: MDPI stays neutral with regard to jurisdictional claims in published maps and institutional affiliations.

(C) 2020 by the authors. Licensee MDPI, Basel, Switzerland. This article is an open access article distributed under the terms and conditions of the Creative Commons Attribution (CC BY) license (http://creativecommons.org/licenses/by/4.0/). 